\title{
COBERTURA MORTA DO SOLO NO CULTIVO DE ALFACE Cv. REGINA 2000, EM JI-PARANÁ/RO
}

\author{
Mulching in lettuce cv. Regina 2000, in Ji-Paraná/RO
}

\author{
Jimmy Elizio de Carvalho', Fabio Zanella', \\ José Hortêncio Mota ${ }^{3}$, Ana Lúcia da Silva Lima ${ }^{4}$
}

\begin{abstract}
RESUMO
Conduziu-se este estudo com o objetivo de avaliar o efeito de diferentes materiais de cobertura do solo na produtividade da alface (Lactuca sativa L. cv. Regina 2000). O delineamento experimental utilizado foi o de blocos casualizados, utilizando-se cinco tratamentos (palha de arroz, palha de café, Brachiaria brizantha L., serragem, testemunha sem cobertura morta) e quatro repetições. A produtividade foi avaliada pelo número de folhas por planta, acúmulo de massa fresca e massa seca. Verificou-se que todos os materiais empregados como cobertura, controlaram a infestação de plantas invasoras. Entretanto, verificou-se uma grande infestação na testemunha promovendo redução de produtividade.
\end{abstract}

Termos para indexação: Lactuca sativa, cobertura morta, plantas invasoras.

\begin{abstract}
The purpose of this research was to evaluate the effect of different mulching materials on lettuce (Lactuca sativa L. cv. Regina 2000) yield. The experimental design was randomized blocks, with five treatments (rice straw, coffee husk, Brachiaria brizantha L., sawing and control without mulching) and four repetitions. The number of leaves per plant and the dry and fresh matter accumulation were evaluated. All materials used as mulching, controlled the weed infestation. However, weed population was greater in the control whit reduction yield in comparison to the others treatments.
\end{abstract}

Index terms: Lactuca sativa, mulching, weed

(Recebido para publicação em 21 de outubro de 2004 e aprovado em 10 de março de 2005)

\section{INTRODUÇÃO}

A alface (Lactuca sativa L.), é uma planta herbácea, anual, pertencente à família Asteraceae, sendo considerada a hortaliça folhosa mais importante na alimentação do brasileiro, o que assegura a essa cultura, expressiva importância econômica. Com uma área cultivada de aproximadamente 30 mil hectares, a produção anual no Brasil é de aproximadamente 2 milhões de toneladas (YURI et al., 2002).

As diferentes cultivares utilizadas entre os olericultores do centro-sul, originaram-se de trabalhos de melhoramento genético conduzidos no Brasil e, ou no exterior. Tais cultivares viabilizam a cultura ao longo do ano, durante a primavera-verão, quando ocorre maior densidade pluviométrica associada à elevadas temperaturas, o que inviabiliza seu cultivo em determinadas regiões do Brasil, e consequientemente elevando seu custo de produção (FILGUEIRA, 2000).

Nas últimas décadas, diversas técnicas foram incorporadas ao cultivo de hortaliças. Dessas técnicas, destaca-se a cobertura morta ou "mulching" que é a prática pela qual se aplica, ao solo, material orgânico ou inorgânico como cobertura de superfície (SOUZA \& RESENDE, 2003).

Dentre os materiais orgânicos utilizados como cobertura morta, pode-se citar palha de café, palha de arroz, bem como serragem e capim, sendo a utilização desses materiais uma prática de baixo custo e de fácil execução (DEUBERT, 1997).

Também é observada a aplicação de filmes plásticos em cobertura, como os de polietileno de diversas cores, sendo o "mulching preto" o mais utilizado por ser de baixo custo e proporcionar a produção de um produto de maior qualidade, uma vez que evita seu contato direto com o solo. No entanto, a utilização de plástico em regiões de temperaturas elevadas, como é o caso de Ji-Paraná-RO, pode ocasionar um excessivo aumento na temperatura do solo. Segundo Muller (1991), uma elevada temperatura do solo pode interferir negativamente na disponibilidade de alguns nutrientes para as plantas, como o cálcio e o fósforo. Além disso, a adoção de cobertura com plástico significa

\footnotetext{
${ }^{1}$ Estudante do curso de Agronomia, Universidade Luterana do Brasil - Centro Universitário de Ji-Paraná - Cx. P. 271 - 78961 -970 - Ji-Paraná, RO Jimmy_agronomy@yahoo.com.br.

${ }^{2}$ Engenheiro Agrônomo, Universidade Luterana do Brasil - Centro Universitário de Ji-Paraná - Cx. P. 271 - 78961 -970. Ji-Paraná, RO zanellaf@yahoo.com.br

${ }^{3}$ Engenheiro Agrônomo, Departamento de Agronomia/Universidade Federal do Mato Grosso do Sul - Cx. P. 533 - $79804-970$ - Dourados, MS hortenciomota@terra.com.br

${ }^{4}$ Bióloga, Universidade Luterana do Brasil - Centro Universitário de Ji-Paraná - Cx. P. 271 - 78961-970 - Ji-Paraná/RO - limaals@yahoo.com.br
} 
um maior custo de produção, pois o plástico é mais caro do que a maioria das coberturas mortas utilizadas na instalação de uma horta.

De acordo com Souza \& Resende (2003), por meio da cobertura do solo, procura-se influenciar positivamente as qualidades físicas, químicas e biológicas do solo, bem como a diminuição da erosão, criando condições ótimas para o crescimento radicular.

Com a cobertura do solo, ocorre uma menor perda de água por evaporação, além de diminuir as oscilações da temperatura do solo (BRAGAGNOLO \& MIELNICZUK, 1990). Além disso, o emprego da cobertura morta reduz a perda de nutrientes por lixiviação (CARTER \& JOHNSON, 1988) e melhora os atributos físicos e químicos do solo (FIALHO et al., 1991).

Outra importante vantagem da utilização da cobertura morta consiste no controle da infestação de plantas daninhas, as quais prejudicam a cultura mediante o estabelecimento de competição por luz solar, água e nutrientes, podendo, dificultar a colheita e comprometer a qualidade da produção (STAL \& DUSKY, 2003), além de ser hospedeira de pragas e doenças.

Segundo (BUZATTI, 1999), a cobertura morta exerce forte influência sobre a germinação das plantas daninhas. Essas influências vão ser de três ordens: $1^{\circ}$ ) física: através da temperatura próxima a superfície do solo, que normalmente é menor. Isto dificulta ou até mesmo inibe a germinação das sementes fotoplásticas positiva, mediante a redução da radiação solar principalmente, através do próprio impedimento da cobertura que faz com que a planta que germine não tenha energia suficiente para passar pela camada de palha. $2^{\circ}$ ) química: trata da liberação de substâncias químicas denominadas aleloquímicos, que são liberados pelos tecidos e órgãos das plantas mortas. Esses aleloquímicos vão atuar sobre o banco de sementes de algumas plantas daninhas impedindo sua germinação. $3^{\circ}$ ) biológico: presença de microorganismos, fungos e bactérias, podem atuar de forma e inviabilizar a germinação de algumas plantas daninhas.

O presente trabalho teve como objetivo avaliar o efeito de quatro tipos de cobertura morta sobre a incidência de plantas daninhas na cultura da alface e sua influência sobre a produtividade nas condições do município de JiParaná, no Estado de Rondônia.

\section{MATERIAL E MÉTODOS}

O experimento foi conduzido, no período de março a junho de 2004, no setor de Olericultura do Centro Universitário Luterano de Ji-Paraná, localizado no município de Ji-Paraná/RO, à 1052'53" de latitude sul e 61³0'45" longitude oeste, com altitude média de $159 \mathrm{~m}$.

O clima da região, segundo a classificação de Köppen, é caracterizado como CWa (tropical-quente e úmido). A temperatura média anual oscila em torno de $25^{\circ} \mathrm{C}$, e a precipitação pluviométrica anual de $2.250 \mathrm{~mm}$, com umidade relativa do ar média de $85 \%$.

O solo da área experimental é caracterizado como Latossolo Amarelo Areno-Argiloso Distróferrico e apresentava, inicialmente, as seguintes características: $\mathrm{pH}$ em água $=5,1 ; \mathrm{P}=1 \mathrm{mg} / \mathrm{dm}^{3} ; \mathrm{K}=0,74 \mathrm{mg} / \mathrm{dm}^{3} ; \mathrm{Ca}=3,2 \mathrm{mg} /$ $\mathrm{dm}^{3} ; \mathrm{Mg}=2,3 \mathrm{mg} / \mathrm{dm}^{3} ; \mathrm{H}+\mathrm{Al}=24,8 \mathrm{mg} / \mathrm{dm}^{3} ; \mathrm{MO}=24,6 \mathrm{~g} /$ $\mathrm{Kg} ; \mathrm{V}=20 \%$.

A calagem foi realizada no preparo dos canteiros, 60 dias antes do transplante. Para isso, utilizou-se o método de saturação por base na quantidade de 2,66 $\mathrm{t} \mathrm{ha}^{-1} \mathrm{de}$ calcário dolomítico com PRNT de 70\%. A adubação orgânica foi realizada com esterco de aviário curtido, na quantidade de $12 \mathrm{tha}^{-1}$. A adubação mineral foi feita com $\mathrm{N}, \mathrm{P}_{2} \mathrm{O}_{5}$ e $\mathrm{K}_{2} \mathrm{O}$, nas quantidades de 40,400 e $150 \mathrm{~kg} \mathrm{ha}^{-1}$, respectivamente.

A adubação orgânica e a adubação mineral foram misturadas e incorporadas ao solo, dez dias antes do transplante das mudas.

A cultivar de alface utilizada foi a Regina 2000, por ter uma boa produtividade e aceitação comercial, além de ser resistente ao mosaico, à queima da saia, tolerante ao calor e ao pendoamento precoce.

A semeadura foi realizada em bandejas de poliestireno expandido contendo 200 células, utilizandose o substrato comercial para hortaliças. As mudas foram transplantadas com 30 dias de idade, para o campo.

Os tratos culturais consistiram de irrigação diária, pulverizações com inseticidas e fungicidas, além de adubação mineral de cobertura utilizando-se $75 \mathrm{~kg} \mathrm{ha}^{-1} \mathrm{de}$ $\mathrm{N}$, aplicado em 03 parcelas: aos 10, 20 e 30 dias após o transplante das mudas. Foi também feita uma adubação foliar com micronutrientes (Basfoliar $\mathrm{CaB}$ ).

O delineamento experimental utilizado foi o de blocos casualizados com cinco tratamentos em quatro repetições. Os tratamentos consistiram na aplicação de cobertura morta com serragem, capim (Brachiaria brizantha L.), palha de café e palha de arroz, formando uma espessura de $2,0 \mathrm{~cm}$ sobre o solo, resultando nas proporções de 111,2; 5,0; 61,2 e 63,7 t ha-1 , respectivamente, além da testemunha que não foi colocado nenhuma cobertura sobre o solo.

Cada parcela constou de cinco fileiras de plantas espaçadas de $0,20 \mathrm{~m} \times 0,20 \mathrm{~m}$ com cinco plantas por fileira,

Ciênc. agrotec., Lavras, v. 29, n. 5, p. 935-939, set./out., 2005 
perfazendo uma área de $1 \mathrm{~m}^{2}$, sendo as linhas laterais consideradas bordaduras, estabelecendo-se, dessa forma, uma área útil de $0,64 \mathrm{~m}^{2}$. A aplicação da cobertura deu-se posteriormente a aplicação da adubação mineral.

As coletas foram realizadas 40 dias a partir do transplante, sendo as plantas cuidadosamente retiradas do solo, com o auxílio de uma pá de jardinagem, procurando-se preservar ao máximo a integridade do sistema radicular. Foram coletadas 6 plantas por parcela para as avaliações que consistiram na obtenção da massa fresca e da massa seca da parte aérea, número de folhas por planta, massa fresca e seca do sistema radicular. Avaliou-se também a incidência de plantas daninhas, por meio da massa fresca e seca das plantas em unidade de área de solo.

Para a obtenção da massa seca, o material foi levado à estufa, com uma temperatura de $\pm 65^{\circ} \mathrm{C}$, durante um período de 72 horas, até atingir massa constante.

As características avaliadas foram submetidas à análise de variância e as médias foram comparadas pelo teste de Tukey a $5 \%$ de probabilidade.

\section{RESULTADOS E DISCUSSÃO}

Observa-se, na Tabela 1, que as plantas consideradas como testemunha apresentaram um número médio de 21 folhas.planta ${ }^{-1}$, sendo este o menor resultado, estando significativamente abaixo dos obtidos nos demais tratamentos, os quais oscilaram entre 35 e 40 folhas.planta ${ }^{-1}$. Isso pode ser atribuído à concorrência com as plantas daninhas (Tabela 1), as quais, devido à sua agressividade e desenvolvimento privaram as plantas de alface de fatores essenciais ao seu desenvolvimento, tais como água, luz e nutrientes.
Para os tratamentos com cobertura: capim, palha de arroz, palha de café e serragem, observa-se que não houve diferença significativa entre os tratamentos, ou seja, todas as coberturas mostraram-se eficientes na produção da alface. Tal resultado comprova que, conforme relatam Sediyama \& Prates (1986), a presença de "mulching" torna os primeiros centímetros do solo um ambiente mais adequado biologicamente, favorecendo uma grande proliferação de raízes superficiais.

Em relação à massa fresca acumulada, obteve-se um valor médio de 56,15 g.planta ${ }^{-1}$ na testemunha, enquanto que nos tratamentos com cobertura, os valores oscilaram entre 212,3 g.planta ${ }^{-1}$ com palha de café e 234,5 g.planta ${ }^{-1}$ no tratamento com capim.

Contudo, a diferença obtida nos tratamentos com cobertura foi apenas visual. O acúmulo de massa seca seguiu tendência similar ao acúmulo de massa fresca, sendo o menor dado médio apresentado pela testemunha, além de não ter ocorrido diferença significativa entre as coberturas.

Os benefícios da cobertura morta na manutenção da produtividade têm sido documentados em alface além de outras hortaliças. Maia Neto (1988), investigando três cultivares de alface, Brasil 221, Babá de Verão e Vitória, constatou que a cobertura morta proporcionou aumentos na massa média das plantas. Na cultura do alho, a utilização de cobertura morta propiciou maior produtividade dos bulbos, em relação ao tratamento sem cobertura (CORRÊEA et al., 2001).

A prática de aplicar capim a cultura do alho é muito comum nos municípios de Inconfidentes e Ouro Fino, região do sul do Estado de Minas Gerais, com o intuito de manter o solo úmido, favorecendo o desenvolvimento da cultura.

TABELA 1 - Folhas.planta ${ }^{-1}$, massa fresca total, massa seca total e infestação de plantas daninhas na alface cv. Regina 2000, cultivada com diferentes coberturas mortas, em Ji-Paraná/RO, junho de 2004.*

\begin{tabular}{|c|c|c|c|c|}
\hline \multirow[t]{2}{*}{ Tratamento } & Folhas. planta ${ }^{-1 * *}$ & $\begin{array}{c}\text { Massa fresca } \\
\text { total** }\end{array}$ & $\begin{array}{c}\text { Massa seca } \\
\text { total** }\end{array}$ & \multirow[t]{2}{*}{$\begin{array}{l}\text { Plantas invasoras }{ }^{* *} \\
\left(\mathrm{~g} \mathrm{de} \mathrm{massa} \mathrm{seca}^{-1} \cdot \mathbf{m}^{-2}\right)\end{array}$} \\
\hline & & \multicolumn{2}{|c|}{ (g.planta $\left.^{-1}\right)$} & \\
\hline Testemunha & $21 \mathrm{~b}$ & $56,15 \mathrm{~b}$ & $1,52 \mathrm{~b}$ & $548,20 \mathrm{a}$ \\
\hline Capim & $40 \mathrm{a}$ & $234,50 \mathrm{a}$ & $7,57 \mathrm{a}$ & $14,63 \mathrm{~b}$ \\
\hline Palha de arroz & $39 \mathrm{a}$ & $221,40 \mathrm{a}$ & $7,74 \mathrm{a}$ & $14,69 \mathrm{~b}$ \\
\hline Palha de café & $35 \mathrm{a}$ & $212,33 \mathrm{a}$ & $7,46 \mathrm{a}$ & $16,62 \mathrm{~b}$ \\
\hline Serragem & $35 \mathrm{a}$ & $218,63 \mathrm{a}$ & $7,85 \mathrm{a}$ & $14,67 \mathrm{~b}$ \\
\hline C.V. (\%) & 12,9 & 6,1 & 6,3 & 16,8 \\
\hline
\end{tabular}

* Letras diferentes significam diferenças estatísticas entre os tratamentos, pelo teste de Tukey, ao nível de 5\% de probabilidade.

**Dados obtidos de plantas com idade de 40 dias após o transplante. 
Já Andreani Júnior \& Silva (2004), em experimentos com plantas de rúcula, concluíram que a cobertura com palha de café proporcionou uma produtividade superior às coberturas com capim, palha de feijão guandu, palha de arroz, serragem e cobertura com plástico em ambos os experimentos, concluindo que a superioridade da casca de café pode estar relacionada a manutenção de uma maior umidade e menor temperatura no solo, fatores estes que foram visíveis durante a condução do experimento.

Em estudo com pimentão, Queiroga et al. (2002) constataram que o tratamento com serragem apresentou valores próximos à testemunha (sem cobertura). Isso pode ser explicado pelo fato de a serragem apresentar uma elevada relação $\mathrm{C} / \mathrm{N}$, o que levaria a uma deficiência de $\mathrm{N}$ no solo (ROBINSON, 1988).

Porém, o mesmo não ocorreu no presente trabalho, em que os dados de produção no tratamento com serragem equivaleram-se aos demais tipos de cobertura. Isso pode ser explicado pelo pouco tempo em que o material de cobertura permaneceu no solo, além disso, não houve incorporação da serragem, o que aceleraria a decomposição desse material, e conseqüentemente a imobilização de $\mathrm{N}$ do solo.

O controle de plantas daninhas foi igualmente eficiente entre os tratamentos em que se empregou cobertura morta (Tabela 1). Na testemunha a densidade de plantas daninhas foi de 548,2 g de massa seca ${ }^{-1} \cdot \mathrm{m}^{-2}$, muito superior aos valores de 14,$69 ; 14,63 ; 14,67$ e 16,62 g de massa seca-1 $\mathrm{m}^{-2}$, obtidos nos tratamentos com casca de arroz, capim, serragem e palha de café, respectivamente. Segundo Maia Neto (1988), a adoção de cobertura morta reduziu substancialmente a infestação de plantas invasoras na cultura da alface, em relação ao tratamento com solo nu.

A menor produtividade da alface cv. Regina 2000 foi obtida nas plantas do tratamento testemunha, o que pode ser atribuído a grande competição com plantas daninhas.

Segundo Lorenzi (2000), as plantas invasoras comprometem, em termos médios, 30 a $40 \%$ da produção das culturas nas regiões tropicais do mundo. Em relação ao controle sobre a infestação de plantas daninhas, a cobertura morta modifica as condições em que as sementes das plantas daninhas germinam, dificultando a emergência das mesmas pela menor incidência de luz, menor amplitude térmica do solo entre o dia e a noite, liberação de aleloquímicos e pela barreira física imposta pela palha (TEASDALE, 1996). Dessa forma, o efeito da cobertura morta na manutenção da produtividade da alface deveuse à supressão das plantas daninhas, o que não ocorreu na testemunha.

\section{CONCLUSÕES}

Para as condições em que foi desenvolvido o presente estudo, pode-se concluir que:

a) A cobertura morta é uma prática indispensável para a manutenção da produtividade da alface, nas condições do município de Ji-Paraná/RO.

b)Todos os materiais empregados como cobertura se mostraram igualmente eficazes no controle de plantas daninhas.

\section{REFERÊNCIAS BIBLIOGRÁFICAS}

ANDREANI JÚNIOR, R.; SILVA, D. A. Influência de diferentes coberturas do solo sobre o desenvolvimento da cultura da rúcula. Horticultura Brasileira, Brasília, v. 22, n. 2, 2004. Suplemento, CD-ROM.

BRAGAGNOLO, N.; MIELNICZUK, J. Cobertura do solo por palha de trigo e seu relacionamento com a temperatura e umidade do solo. Revista Brasileira de Ciência do Solo, Viçosa, v. 14, n. 3, p. 369-374, 1990.

BUZATTI, W. J. de S. Controle de plantas daninhas no sistema plantio direto na palha. In: PAULETTI, V.; SEGANFREDO, R. Plantio direto: atualização tecnológica. São Paulo: Fundação Cargill/Fundação ABC, 1999. p. 97-111.

CARTER, I.; JOHNSON, C. Influence of different types of mulches on eggplant production. Hortscience, Alexandria, v. 23, n. 1, p. 143-145, 1988.

CORREAA, T. M.; RESENDE, F. V.; OLIVEIRA, P. S. R. Cobertura morta de solo e parcelamento da adubação nitrogenada e potássica em alho proveniente de cultura de tecidos. Horticultura Brasileira, Brasília, v. 19, n. 2, 2001. Suplemento, CD-ROM.

DEUBERT, R. Ciências das plantas infestantes: manejo. Campinas: [s.n.], 1997. 285 p.

FIALHO, J. F.; BORGES, N. F.; BARROS, N. F. Cobertura vegetal e as características químicas e físicas e atividade da microbiótica de um latossolo vermelho-amarelo distrófico. Revista Brasileira de Ciência do Solo, Viçosa, v. 15 , n. 1, p. 21-28, 1991.

FILGUEIRA, F. A. R. Novo manual de olericultura: agrotecnologia moderna na produção e comercialização de hortaliças. Viçosa: UFV, 2000. 402 p.

Ciênc. agrotec., Lavras, v. 29, n. 5, p. 935-939, set./out., 2005 
LORENZI, H. Plantas daninhas do Brasil: terrestres, aquáticas, parasitas e tóxicas. 3. ed. Nova Odessa: Instituto Plantarum, 2000. 237 p.

MAIA NETO, J. M. Efeito da cobertura morta sobre o comportamento de cultivares de alface (Lactuca sativa L.) no município de Mossoró. Mossoró: [s.n.], 1988. 16 p. (Coleção Mossoroense, série B, 515).

MULLER, A. G. Comportamento térmico do solo e do ar em alface (Lactuca sativa L.) para diferentes tipos de cobertura do solo. 1991. 77 f. Dissertação (Mestrado) - Escola Superior de Agricultura de Luiz de Queiroz, Piracicaba, 1991.

QUEIROGA, R. C. F.; NOGUEIRA, I. C. C.; BEZERRA NETO, F.; MOURA, A. R. B.; PEDROSA, J. F. Utilização de diferentes materiais como cobertura morta do solo no cultivo de pimentão. Horticultura Brasileira, Brasília, v. 20, n. 3, p. 416-418, 2002.

ROBINSON, D. W. Mulches and herbicides in ornamental plantings. Hortscience, Alexandria, v. 23, n. 6, p. 547-552, 1988.
SEDIYAMA, G. C.; PRATES, J. E. O microclima: possibilidades de modificação. Informe Agropecuário, Belo Horizonte, v. 12, n. 138, p. 39-47, 1986.

SOUZA, J. L.; RESENDE, P. Manual de horticultura orgânica. Viçosa: Aprenda Fácil, 2003. 564 p.

STAL, M. W.; DUSKY, A. J. Weed control in leafy vegetables: lettuce, endive, escarole and spinach. 2003. Disponível em: <http//www edis.ifas.ufl.edu/ BODY_WG031>. Acesso em: 27 maio 2004.

TEASDALE, J. R. Contribution of cover crops to weed management in sustainable agricultural systems. Journal Product Agricultural, [S.1.], v. 9, p. 475-479, 1996.

YURI, J. E.; MOTA, J. H.; SOUZA, R. J.; RESENDE, G. M.; FREITAS, S. A. C.; RODRIGUES JÚNIOR, J. C. Alface americana: cultivo comercial. Lavras: UFLA, 2002. 49 p. (Texto Acadêmico, 13). 